\title{
Prevalence of asthma in 13-14 yr-old schoolchildren across Israel
}

\author{
T. Shohat***, G. Golan*, R. Tamir***, M.S. Green***, I. Livne ${ }^{+}$, Y. Davidson ${ }^{++}$, \\ G. Harari*, B.Z. Garty
}

\begin{abstract}
Prevalence of asthma in 13-14 yr-old schoolchildren across Israel. T. Shohat, G. Golan, R. Tamir, M.S. Green, I. Livne, Y. Davidson, G. Harari, B.Z. Garty. (C) ERS Journals Ltd 2000 ABSTRACT: There is evidence that the incidence and severity of asthma are increasing worldwide, but there are limited data on asthma in Israel. The aim of this study was to investigate the prevalence and severity of asthma and asthma symptoms in 13-14 yr-old schoolchildren in Israel.

The self-completed questionnaire used was a modified version of that developed by the International Study of Asthma and Allergies in Childhood (ISAAC), and was administered to a national sample of 12,918 children.

The prevalence of asthma ever, wheezing ever and wheezing in the last 12 months were $13.7,23.8$ and $17.9 \%$ respectively. Significantly higher rates of a history of asthma and asthma symptoms were observed in Jews compared with Arabs. Although asthma ever was more prevalent in males than in females, asthma symptoms were significantly more common in females. The type of area of residence had no effect on the prevalence of wheezing. The ethnic differences in the prevalence of asthma persisted after controlling for sex, district of residence and level of urbanization.

The prevalence of both asthma and asthma symptoms in Israel are slightly above the mean reported from 10 other countries in Europe and the Far-East.

Eur Respir J 2000; 15: 725-729.
\end{abstract}

There is growing evidence that morbidity and mortality caused by asthma are increasing in many parts of the world [1-3]. In Israel, there is limited information on the prevalence of asthma in schoolchildren. In a large-scale survey conducted in 1992, parents of 2,160 children aged 6-10 yrs completed questionnaires. The results indicated greater prevalence of asthma in Jews than in Arabs, and in urban than in rural areas [4]. In addition, there are several reports on asthma in 17-yr-olds examined prior to induction into the military [5-7]. These studies demonstrated a greater prevalence of asthma in those born in 1969-1971 than in those born in 1963-1965 [5]. A significant increase in the prevalence of asthma ever, from $5.7 \%$ in 1980 to $11.2 \%$ in 1989 was demonstrated in a study carried out in four cohorts of schoolchildren living around a new power plant in Israel [8].

In the absence of a uniform definition of asthma, it has been difficult to compare the results of such studies with others performed in different places and at different time periods. To counter this problem, the International Study of Asthma and Allergies in Childhood (ISAAC) formulated a questionnaire for the purpose of making international comparisons of asthma prevalence and severity [9]. This questionnaire has been used in $>56$ countries, in 155 collaborating centres, and has allowed worldwide assessment of the self-reported symptoms of asthma, allergic rhinitis and atopic eczema $[10,11]$.

\begin{abstract}
*The Israel Center for Disease Control, Israel Ministry of Health, Tel Hashomer, **Dept of Epidemiology and Preventive Medicine, Faculty of Medicine, Tel-Aviv University, Tel Aviv, ${ }^{* * *}$ Clinical Immunology and Allergy Unit, Rabin Medical Center, Petach Tikva, ${ }^{+}$Israel Ministry of Education, Jerusalem, ${ }^{++}$Public Health Services, Israel Ministry of Health, Jerusalem, and "Pediatric Dept B and Kipper Institute of Allergy and Immunology, Schneider Children's Medical Center and the Faculty of Medicine, TelAviv University, Petach Tikva, Israel.
\end{abstract}

Correspondence: T. Shohat, Israel Center for Disease Control, Gertner Institute, Sheba Medical Center, Tel Hashomer 52621, Israel, Fax: 97235349881

Keywords: Asthma, International Study of Asthma and Allergies in Childhood, prevalence, schoolchildren

Received: June 151999

Accepted after revision December 131999
The aim of the present study was to use the ISAAC protocol to investigate the prevalence and severity of asthma and asthma-related symptoms in Israel in a national sample of schoolchildren aged 13-14 yrs.

\section{Materials and methods}

\section{Sample}

The calculated sample size that would allow meaningful comparisons between Jews and Arabs, and residents of urban and rural areas was 10,000 . To obtain a representative sample of 13-14-yr-old schoolchildren, 141 schools were chosen at random by district from a list of schools provided by the Israel Ministry of Education. The sampling unit was a school; for each school sampled, all eighthgrade children were included in the study. The number of schools selected from each district was weighted for the total number of eighth graders in that district and the number of children attending each school. For technical logistical reasons, the following population groups were not included: Druze and Bedouin, comprising $26 \%$ of the Arab population, as well as some Ultra-Orthodox Jews, comprising $5 \%$ of the Jewish population.

The study was carried out during the first 2 weeks of May 1997. The parents of the children in the selected 
schools received an explanatory letter with a reply slip to return if they did not want their child to participate in the study. Children who were absent from school on the day of the study were asked to complete the questionnaire on a specified day in the following month.

\section{Questionnaire}

The entire ISAAC standard written core questionnaire for wheezing and asthma was used [9]. The items covered wheezing ever, wheezing in the last 12 months, frequency of attacks of wheezing, asthma ever, exercise- related wheezing in the last 12 months, dry cough at night in the absence of cold in the last 12 months, speech-limiting wheezing in the last 12 months and sleep disturbance due to wheezing in the last 12 months. A question was added regarding a current diagnosis of asthma. All questionnaires were completed in class, and teachers were instructed not to help the children with the answers. All responses were anonymous.

\section{Definitions}

Children who answered "yes" to the question "Do you have asthma or spastic bronchitis?" were considered to have current asthma. The term "spastic bronchitis" was used as this is more commonly used by the public. In accordance with the definition of the Israel Ministry of Interior Affairs, residential areas with $<2,000$ inhabitants were considered rural, and those with $\geq 2,000$ residents were considered urban. The assignment of a district to each place of residence was done according to the allocation of the Israel Ministry of Interior Affairs. The severity of asthma was assessed by means of the prevalence of speech-limiting wheezing and the percentage of children who had had more frequent attacks (four or more) of wheezing in the last 12 months.

\section{Statistical analysis}

Statistical analysis was performed with the SAS package (SAS Institute, Inc., Cary, NC, USA). In accordance with ISAAC guidelines, "missing" responses were included in the denominators for the univariate analysis. Comparisons between the prevalence of asthma and asthma symptoms by sex, ethnic group and place of residence were performed using the Chi-squared test. To evaluate variables associated with asthma while controlling for possible confounding variables, the multivariate logistic regression model was used and adjusted odds ratios were calculated.

\section{Results}

\section{Response rate}

The original sample included 14,041 schoolchildren from 141 schools. Of these, 1,123 children were excluded for the following reasons: 1,030 questionnaires (16 schools) never arrived at their destination and 93 children (10 schools) had severe mental retardation. The revised sample included 12,918 schoolchildren (9,961 Jews and 2,957 Arabs) of whom 11,157 completed the questionnaire (overall response rate, $86.4 \%$ ). The reasons for nonresponse are summarized in table 1 . The response rate of the Arab children was significantly higher than that of the Jewish children (91.1 versus $85.0 \%, \mathrm{p}=0.01)$. A further 1,100 questionnaires were not included in the analysis for the following reasons: 994 (seven schools) were lost in the post; 36 (one class) were excluded, since 23 of the children reported having been diagnosed with asthma (information which was refuted by the school nurse); and 70 because the children did not identify their sex.

\section{Prevalence of asthma}

The prevalence of current asthma and asthma ever by ethnic group, sex and urbanization are reported in table 2 . Significantly higher rates were observed in Jews than in Arabs (7.8 versus $4.9 \%$ for current asthma and 16.2 versus $6.7 \%$ for asthma ever, $\mathrm{p}=0.001)$. Compared with females, males had a slightly greater prevalence of current asthma $(\mathrm{p}=0.26)$, and a significantly higher rate of asthma ever ( 15.0 versus $12.5 \%, \mathrm{p}=0.001)$. Higher rates of current asthma and of asthma ever were noted in urban areas than in rural areas $(p=0.03$ and 0.008 , respectively). Analysis by district yielded slight yet significant differences for both current asthma and asthma ever, with the lowest rates in the Northern district and Jerusalem district (table 3 ). These differences remained when the analysis was carried out separately for the Jewish population. No significant differences were noted between Jewish children born in Israel or elsewhere. There were also no differences in prevalence between the 13- and-14 yr-olds.

\section{Symptoms of asthma}

Wheezing ever, was significantly more common in Jews than in Arabs ( 28.2 versus $11.4 \%, \mathrm{p}=0.001$ ), as were symptoms that are generally associated with more severe disease, such as multiple attacks of wheezing in the last 12 months, speech-limiting attacks and sleep disturbance caused by wheezing in the last 12 months (table 2). Compared with males, females had significantly higher rates of wheezing attacks in the last 12 months, exercise-related wheezing, speech-limiting wheezing and dry cough at night (table 2). The only significant difference noted for symptoms of asthma by type of area of residence was a significantly higher prevalence of dry cough at night in the last 12 months in urban areas $(\mathrm{p}=0.03)$ (table 2$)$. The

Table 1. - Reasons for nonresponse by ethnic group

\begin{tabular}{lrrc}
\hline & $\begin{array}{c}\text { Original } \\
\text { sample }\end{array}$ & \multicolumn{1}{c}{ Jews } & Arabs \\
\hline Subjects n & 12918 & 9961 & 2957 \\
Parents refused n(\%) & $305(2.4)$ & $167(1.6)$ & $138(4.7)$ \\
$\begin{array}{l}\text { Absence from school } \\
\mathrm{n}(\%)\end{array}$ & $1251(9.7)$ & $1152(11.6)$ & $99(3.3)$ \\
$\begin{array}{l}\text { Schools refused n(\%) } \\
\text { Incomplete }\end{array}$ & $78(0.6)$ & $78(0.8)$ & - \\
$\quad \begin{array}{l}\text { questionnaires n(\%) } \\
\text { Total n(\%) }\end{array}$ & $127(0.9)$ & $101(1.0)$ & $26(0.9)$ \\
\hline
\end{tabular}


Table 2. - Prevalence of asthma and asthma symptoms by ethnic group, sex and urbanization

\begin{tabular}{|c|c|c|c|c|c|c|c|}
\hline & \multicolumn{7}{|c|}{ Prevalence $\%$} \\
\hline & Total & Jews & Arabs & Males & Females & Urban & Rural \\
\hline Subjects $n$ & 10057 & 7436 & 2621 & 4990 & 5067 & 8500 & 1457 \\
\hline Current asthma & 7.0 & $7.8^{+}$ & 4.9 & 7.3 & 6.8 & $7.3 *$ & 5.7 \\
\hline Asthma ever & 13.7 & $16.2^{+}$ & 6.7 & $15.0^{+}$ & 12.5 & $14.2 * *$ & 11.5 \\
\hline Wheezing ever & 23.8 & $28.2^{+}$ & 11.4 & $22.2^{+}$ & 25.4 & 24.2 & 23.4 \\
\hline Wheezing in the last 12 months & 17.9 & $20.8^{+}$ & 10.0 & $16.1^{+}$ & 19.8 & 18.6 & 16.0 \\
\hline $\begin{array}{l}\geq 4 \text { attacks of wheezing in the } \\
\text { last } 12 \text { months }\end{array}$ & 4.9 & $5.8^{+}$ & 2.7 & 4.8 & 5.2 & 5.2 & 4.1 \\
\hline $\begin{array}{l}\text { Exercise-related wheezing in the } \\
\text { last } 12 \text { months }\end{array}$ & 19.2 & $22.8^{+}$ & 9.3 & $15.9^{+}$ & 22.5 & 19.4 & 19.5 \\
\hline $\begin{array}{l}\text { Speech-limiting wheezing in the } \\
\text { last } 12 \text { months }\end{array}$ & 6.2 & $6.7^{+}$ & 4.8 & $4.7^{+}$ & 7.9 & 6.3 & 5.9 \\
\hline \multicolumn{8}{|l|}{ Sleep disturbance in the last 12 months } \\
\hline$<1 \cdot$ week $^{-1}$ & 4.6 & $5.2^{+}$ & 2.8 & $4.1^{+}$ & 5.1 & 4.7 & 4.5 \\
\hline$\geq 1 \cdot$ week $^{-1}$ & 3.4 & 2.3 & 6.4 & 2.7 & 4.0 & 3.5 & 2.4 \\
\hline $\begin{array}{l}\text { Dry cough at night in the absence of } \\
\text { cold in the last } 12 \text { months }\end{array}$ & 22.9 & $24.2^{+}$ & 19.3 & $20.3^{+}$ & 25.5 & $23.4^{*}$ & 20.9 \\
\hline
\end{tabular}

Comparisons were performed between: Jews and Arabs; males and females; and urban residents and rural residents. *: $\mathrm{p}<0.05$; **: $\mathrm{p}<0.01 ;{ }^{+}: \mathrm{p}=0.001$.

prevalence of symptoms of asthma in different districts resembled the distribution of asthma (table 3), with the Northern district, and Jerusalem district having lower rates compared with Tel Aviv district and the Central and Southern districts. In particular, low rates of exerciserelated wheezing and speech-limiting wheezing were found in the Northern district.

\section{Multivariate analyses}

Multiple logistic regression analysis was performed to evaluate the effect of the demographic factors on the prevalence of asthma and asthma symptoms (table 4). Population group (Jewish) was significantly associated with current asthma (OR (odds ratio) 1.50, 95\% confidence interval (CI) 1.18-1.89, $\mathrm{p}=0.0007$ ), asthma ever (OR $2.38,95 \%$ CI $1.96-2.89, \mathrm{p}=0.0001$ ), wheezing ever (OR $2.62,95 \%$ CI $2.25-3.05, \mathrm{p}=0.0001)$ and wheezing in the last 12 months (OR 2.11, 95\% CI 1.79-2.48, $\mathrm{p}=0.0001$ ). Sex (male) was significantly associated with asthma ever, whereas symptoms of asthma such as wheezing ever and wheezing in the last 12 months were significantly lower in males than in females. When the Northern district was taken as a reference, Tel Aviv district and the Central and Southern districts showed, in general, significantly higher prevalences of asthma and asthma symptoms (ORs 1.261.48). In the multivariate analysis, the effect of area of residence lost its significance, and only wheezing in the last 12 months reached borderline significance (OR 1.16, 95\% CI 0.99-1.36, p=0.07).

\section{Discussion}

This study provides, for the first time, the prevalence rates of asthma and asthma symptoms in a nationwide sample of schoolchildren in Israel. The prevalence rates among 13-14-yr-old schoolchildren were $7.0 \%$ for current asthma, $13.7 \%$ for asthma ever, $23.8 \%$ for wheezing ever and $17.9 \%$ for wheezing in the last 12 months. The use of the standard ISAAC questionnaire, which has been proven to be a valid instrument for the determination of asthma symptoms [12], permits comparison of Israel with other countries.

Table 3. - Prevalence of asthma diagnosed, asthma symptoms and allergy by district

\begin{tabular}{|c|c|c|c|c|c|c|c|}
\hline & \multicolumn{7}{|c|}{ Prevalence \% } \\
\hline & North & Haifa & Central & Tel Aviv & Jerusalem & South & p-value \\
\hline Subjects $n$ & 2304 & 2143 & 1803 & 1609 & 915 & 1283 & \\
\hline Current asthma & 4.9 & 7.4 & 7.4 & 8.1 & 5.8 & 9.1 & 0.001 \\
\hline Asthma ever & 9.0 & 12.3 & 14.8 & 19.5 & 11.4 & 17.5 & 0.001 \\
\hline Wheezing ever & 15.5 & 21.8 & 27.7 & 30.2 & 22.3 & 29.7 & 0.001 \\
\hline Wheezing in the last 12 months & 12.5 & 17.0 & 21.1 & 21.8 & 15.8 & 21.7 & 0.001 \\
\hline$\geq 4$ attacks of wheezing in the last 12 months & 2.9 & 5.5 & 6.2 & 6.0 & 4.1 & 5.5 & 0.001 \\
\hline Exercise-related wheezing in the last 12 months & 12.9 & 18.2 & 22.0 & 23.7 & 21.2 & 21.7 & 0.001 \\
\hline Speech-limiting wheezing in the last 12 months & 4.5 & 6.7 & 7.0 & 6.8 & 5.8 & 7.0 & 0.005 \\
\hline \multicolumn{8}{|l|}{ Sleep disturbance in the last 12 months } \\
\hline$<1 \cdot$ week $^{-1}$ & 3.4 & 4.7 & 4.8 & 4.9 & 4.3 & 6.0 & 0.001 \\
\hline$\geq 1 \cdot$ week $^{-1}$ & 4.1 & 4.7 & 2.8 & 2.4 & 2.6 & 2.5 & \\
\hline $\begin{array}{l}\text { Dry cough at night in the absence of cold in the } \\
\text { last } 12 \text { months }\end{array}$ & 19.1 & 22.3 & 26.3 & 22.1 & 9.1 & 24.9 & 0.001 \\
\hline
\end{tabular}


Table 4. - Effects of demographic factors on the reported prevalence of asthma and asthma symptoms

\begin{tabular}{|c|c|c|c|c|c|c|c|c|}
\hline & \multicolumn{2}{|c|}{ Current asthma } & \multicolumn{2}{|c|}{ Asthma diagnosed } & \multicolumn{2}{|c|}{ Wheezing ever } & \multicolumn{2}{|c|}{$\begin{array}{l}\text { Wheezing in the } \\
\text { last } 12 \text { months }\end{array}$} \\
\hline & OR & $95 \% \mathrm{CI}$ & OR & $95 \% \mathrm{CI}$ & OR & $95 \% \mathrm{CI}$ & OR & $95 \% \mathrm{CI}$ \\
\hline \multicolumn{9}{|c|}{ Population group } \\
\hline Arabs & 1.00 & - & 1.00 & - & 1.00 & - & 1.00 & - \\
\hline Jews & 1.50 & $1.18-1.89$ & 2.38 & $1.96-2.89$ & 2.62 & $2.25-3.05$ & 2.11 & $1.79-2.48$ \\
\hline \multicolumn{9}{|l|}{ Sex } \\
\hline Female & 1.00 & - & 1.00 & - & 1.00 & - & 1.00 & - \\
\hline Male & 1.11 & $0.95-1.29$ & 1.26 & $1.12-1.41$ & 0.85 & $0.78-0.94$ & 0.79 & $0.71-0.88$ \\
\hline \multicolumn{9}{|c|}{ Urbanization } \\
\hline Rural & 1.00 & - & 1.00 & - & 1.00 & - & 1.00 & - \\
\hline Urban & 1.25 & $0.98-1.60$ & 1.17 & $0.98-1.40$ & 0.97 & $0.86-1.13$ & 1.16 & $0.99-1.36$ \\
\hline \multicolumn{9}{|l|}{ District } \\
\hline Northern & 1.00 & - & 1.00 & - & 1.00 & - & 1.00 & - \\
\hline Haifa & 1.36 & $1.05-1.76$ & 1.12 & $0.92-1.37$ & 1.15 & $0.98-1.35$ & 1.14 & $0.95-1.35$ \\
\hline Tel Aviv & 1.25 & $0.93-1.69$ & 1.48 & $1.20-1.85$ & 1.39 & $1.17-1.67$ & 1.23 & $1.01-1.50$ \\
\hline Central & 1.24 & $0.93-1.64$ & 1.19 & $0.97-1.48$ & 1.34 & $1.13-1.59$ & 1.28 & $1.07-1.55$ \\
\hline Jerusalem & 0.93 & $0.65-1.33$ & 0.86 & $0.66-1.12$ & 1.00 & $0.81-1.23$ & 0.92 & $0.73-1.16$ \\
\hline Southern & 1.44 & $1.10-1.96$ & 1.29 & $1.03-1.63$ & 1.34 & $1.11-1.61$ & 1.22 & $1.00-1.50$ \\
\hline
\end{tabular}

OR: adjusted odds ratio; $\mathrm{CI}$; confidence interval.

There are no comparable studies in Israel. In a study carried out on schoolchildren (6-10 yrs old) in Israel, the overall prevalence of asthma reported by the parents was $6.4 \%$, close to the rate in the present study [4]. In another study, carried out on 13-14-yr-old schoolchildren, as part of a health monitoring system operating in the vicinity of a new power plant, the prevalence of asthma ever was $11.2 \%$ in 1989 [8]. A lower prevalence of asthma $(2.5 \%)$ was found in 1989 in 17-yr-old adolescents examined in the drafting office [7].

On an international basis, marked variations in the prevalence of asthma symptoms, with up to 15 -fold differences between countries, was reported from phase 1 of the ISAAC $[10,11]$. Studies of the same age group in Malta, Uruguay, Kuwait and Panama showed similar prevalence rates of asthma ever, wheezing ever and wheezing in the last 12 months. Lower rates were reported from Greece, China, Hong Kong, Finland, Morocco and Singapore, and higher rates from the UK, New Zealand, Australia, Canada, the USA, Australia and Ireland [10, 11, 13-20].

The present study demonstrates significantly higher prevalence rates of asthma and asthma symptoms in Jews than in Arabs. These differences remained significant in the multivariate analysis. Since the differences in prevalence were not confined only to the diagnosis of asthma, but extended also to wheezing ever, wheezing attacks in the last 12 months and severe attacks limiting speech, the authors believe that these findings cannot be attributed solely to underdiagnosis of asthma in the Arab population due to limited accessibility to health services. Furthermore, population group differences in the prevalence of asthma in Israel had previously been reported in 6-10-yr-old schoolchildren [4].

In that study, the prevalence in Arabs living in rural areas was significantly lower than that in Jews living in rural areas (2.9 versus $8.7 \%)$. There was also a significant difference in the prevalence of asthma between Arabs and Jews living in urban areas (6.6 versus $9.2 \%$ ). Similarly, in the present study, the population group differences in the prevalence of asthma persisted after controlling for sex, area of residence and district. Since the response rate in the Arab children in the present study was significantly higher than that in the Jewish children (table 1), mainly because more Jewish children were absent from school, the prevalence of asthma and asthma symptoms in Jewish children could be higher than estimated, and so also the differences in the prevalence between Jews and Arabs. It is possible that these population group differences could be attributed to other confounders that were not controlled in this study (i.e. socioeconomic status).

Males reported asthma ever more often than females, and there was no significant sex difference in the prevalence of current asthma. However, symptoms of asthma and parameters that are generally associated with more severe disease were significantly more prevalent in females. Similar findings were reported from the UK [18], where female children reported more wheezing in the last 12 months, but less asthma ever. Significantly higher rates of asthma symptoms in females were also reported in a study carried out in four countries: Australia, England, Germany and New Zealand [19]. These findings are in accordance with studies showing a male predominance for wheezing during the first decade of life, which is reversed around the time of puberty [21, 22]. In Hong Kong, higher prevalences of respiratory symptoms were found in male schoolchildren [16], but, when severe respiratory symptoms were considered, the sex difference became less obvious. Although one explanation for the observed sex difference in the severity of asthma could be a tendency of females to overestimate the severity of the disease, the fact that this is a worldwide observation supports this difference being real.

In the present study, urban areas had slightly higher prevalence of current asthma and asthma ever than rural areas. However, these differences were not significant in the multivariate analysis. Only a few studies have addressed the question of the association between level of urbanization and the prevalence of asthma. Lower rates of asthma in children living in rural areas were reported from Israel [4]. In Italy, a greater degree of urbanization was associated with chronic cough and nocturnal cough but 
not with increased prevalence of wheezing [23]. In contrast, higher prevalence rates of asthma and wheeze were found in nonmetropolitan areas than in metropolitan areas in the UK [18]. Since the term "rural" areas was used for small places of $<2,000$ residents in the present study, whereas in other studies it was used to describe cities of $<100,000$ inhabitants, the results are not really comparable [18, 23].

Within Israel, the Northern and Jerusalem districts had the lowest prevalence rates of asthma and asthma symptoms, whereas the Tel Aviv and Southern districts had the highest rates. These differences remained significant in a multivariate analysis. These findings are, in part, in agreement with a previous study on 17-yr-old adolescents, which showed lower prevalences of asthma in the Northern and Jerusalem districts, but, in contrast with the present study, also in the Southern district [5]; however, the definition of the districts was different in the earlier study. The geographic differences in asthma rates may be explained by the higher altitude of the Northern and Jerusalem districts, and by different levels of air pollutants in these districts [24]. An association between asthma morbidity and levels of air pollutants was reported in the Haifa and Tel Aviv districts [25, 26].

In conclusion, the present study provides data which could serve as a reliable baseline for future comparative studies on the prevalence of asthma and asthma symptoms in Israel. The observed population group differences between Jews and Arabs should be further explored and might offer some clues as to the pathogenesis of this disease.

\section{References}

1. Ninan TK, Russell G. Respiratory symptoms and atopy in Aberdeen schoolchildren: evidence from two surveys 25 years apart. BMJ 1992; 304: 873-875.

2. Anderson HR. Is asthma really increasing? Paediatr Respir Med 1993; 1: 6-10.

3. Burr ML, Butland BK, King S, Vaughan-Williams E. Changes in asthma prevalence: two surveys 15 years apart. Arch Dis Child 1989; 64: 1452-1456.

4. Amir J, Horev Z, Jaber L, et al. Prevalence of asthma in Israeli schoolchildren. Isr J Med Sci 1992; 28: 789-792.

5. Auerbach I, Springer C, Godfrey S. Total population survey of the frequency and severity of asthma in 17 year old boys in an urban area in Israel. Thorax 1993; 48: 139141.

6. Sacher Y, Laor A, Danon YL. Longitudinal study on the prevalence of asthma among Israeli young adults. Isr $J$ Med Sci 1994; 30: 564-572.

7. Laor A, Cohen L, Danon YL. Effects of time, sex, ethnic origin, and area of residence on prevalence of asthma in Israeli adolescents. BMJ 1993; 307: 841-844.

8. Goren AI, Hellman S. Changing prevalence of asthma among schoolchildren in Israel. Eur Respir $J$ 1997; 10: 2279-2284.

9. Asher MI, Keil U, Anderson HR, et al. International Study of Asthma and Allergies in Childhood (ISAAC): rationale and methods. Eur Respir J 1995; 8: 483-491.

10. The International Study of Asthma and Allergies in Childhood (ISAAC) Steering committee. Worldwide variation in prevalence of symptoms of asthma, allergic rhinocon- junctivitis, and atopic eczema: ISAAC. Lancet 1998; 351 : $1225-1232$.

11. The International Study of Asthma and Allergies in Childhood (ISAAC) Steering committee. Worldwide variations in the prevalence of asthma symptoms: the International Study of Asthma and Allergies in Childhood. Eur Respir $J$ 1998; 12: 315-335.

12. Jenkins MA, Clarke JR, Carlin JB, et al. Validation of questionnaire and bronchial hyperresponsiveness against respiratory physician assessment in the diagnosis of asthma. Int J Epidemiol 1996; 25: 609-616.

13. Busquets RM, Anto JM, Sunyer J, Sancho N, Vall O. Prevalence of asthma related symptoms and bronchial responsiveness to exercise in children age 13-14 yrs in Barcelona, Spain. Eur Respir J 1996; 9: 2094-2098.

14. Montefort S, Lenicker HM, Caruna S, Agius Muscat H. Asthma, rhinitis and eczema in Maltese 13-15 year-old schoolchildren - prevalence, severity and associated factors [ISAAC]. Clin Exp Allergy 1998; 28: 1089-1099.

15. Stewart AW, Asher MI, Clayton TO, et al. The effect of season of response to ISAAC questions about asthma, rhinitis and eczema in children. Int J Epidemiol 1997; 26: 126-136.

16. Leung R, Wong G, Lau J, et al. Prevalence of asthma and allergy in Hong Kong schoolchildren: an ISAAC study. Eur Respir J 1997; 10: 354-360.

17. Goh DYT, Chew FT, Quek SC, et al. Prevalence and severity of asthma, rhinitis, and eczema in Singapore schoolchildren. Arch Dis Child 1996; 74: 131-135.

18. Kaur B, Anderson HR, Austin J, et al. Prevalence of asthma symptoms, diagnosis, and treatment in 12-14 year old children across Great Britain (International Study of Asthma and Allergies in Childhood, ISAAC UK). BMJ 1998; 316: 118-124.

19. Pearce N, Weiland S, Keil U, et al. Self-reported prevalence of asthma symptoms in children in Australia, England, Germany and New Zealand: an international comparison using the ISAAC protocol. Eur Respir $J$ 1993; 6: 1455-1461.

20. Pekkanen J, Remes ST, Husman T, et al. Prevalence of asthma symptoms in video and written questionnaires among children in four regions of Finland. Eur Respir $J$ 1997; 10: 1787-1794.

21. Venn A, Lewis S, Cooper M, Hill J, Britton J. Questionnaire study of effect of sex and age on the prevalence of wheeze and asthma in adolescence. BMJ 1998; 316 : 1945-1946.

22. Anderson HR, Pottier AC, Strachan DP. Asthma from birth to age 23: incidence and relation to prior and concurrent atopic disease. Thorax 1992; 47: 537-542.

23. SIDRIA (Italian Studied on Respiratory Disorders in Childhood and the Environment). Asthma and respiratory symptoms in 6-7 yr old Italian children: gender, latitude, urbanization and socioeconomic factors. Eur Respir $J$ 1997; 10: 1780-1786.

24. Anonymous. Statistical Abstracts of Israel. Jerusalem, Central Bureau of Statistics, 1998.

25. Goren AI, Hellman S, Brenner S, Egoz N, Rishpon S. Prevalence of respiratory conditions among schoolchildren exposed to different levels of air pollutants in the Haifa Bay Area, Israel. Environ Health Perspect 1990; 89: 225-231.

26. Garty BZ, Kosman E, Ganor F, et al. Emergency room visits of asthmatic children, relation to air pollution, weather and airborne allergens. Ann Allergy Asthma Immunol 1998; 81: 563-570. 